\title{
A NEW METHOD OF APPROACHING EXTREME STORM EVENTS FOR DESIGN LEVEL OR RISK ANALYSIS
}

\author{
Gabriele Goennert $^{1}$, Birgit Gerkensmeier ${ }^{1}$
}

\begin{abstract}
The North Sea coast is seriously threatened by storm surges. Climate change and its consequences, such as a rising sea level, will have serious effects on the safety of people and economic assets in coastal areas. Within the joint research project XtremRisK (bmbf-funded) the Agency of roads bridges and Waters of the Free and Hanseatic City of Hamburg developed a new method to calculate extreme storm surge events. The purpose of the research work, to calculated physically feasible extreme events is given consideration by detailed analyses of the single storm-surge components (tide, external surge from the Atlantic and wind surge) and their non-linear interactions by combining deterministic-empirical, statistical and numerical methods. The non-linear interactions can be comprised by hydrodynamic equations such as equation of momentum, continuity equation and volume balance. The claim to develop a comprehensive and physically feasible method is satisfied by the diversity of methodical approaches for analyzing the storm surge components and their interaction processes. Therefore a 2-method concept is developed on the basis of empirical and numerical approaches. The resultant new method is a new way of calculating extreme storm surges and can be used within new design concepts to calculate design level heights or could be a part of risk analysis.
\end{abstract}

Keywords: extreme event, storm surge, storm surge components, non-linear interaction

\section{INTRODUCTION}

Most of the world's coastal areas are affected by storm surges. Coastal regions of marginal seas, delta coasts and estuarine areas are particularly affected. At the same time, coastal regions are preferred settlement and industrial areas with a high population density and valuable properties. As a consequence, these areas are highly vulnerable to flood events and the costs of flood damage in these regions can be very high. One of the most seriously affected European coastal regions is the North Sea coast, where storm surges constitute the major geophysical risk (Gönnert et al. 2001). Climate change and its consequences will increase the risk of floods and may have serious consequences for the safety of people and assets in coastal areas. In combination with a further increase of coastal population (Small and Nicholls 2003), rising sea level will be one of the major effects of climate change on storm surges that will threaten the coastal regions.

To evaluate the consequences of climate change, it is necessary to assess extreme storm surge events as a first step under the current climate conditions. In a second step, scenarios of potential sea level rises are identified and investigated to evaluate future extreme event scenarios. Based on these scenarios, it will be possible to determine the risk for specific locations and to develop mitigation strategies.

The project XtremRisK (Extreme Storm Surges at Open Coasts and Estuarine Areas - Risk Assessment and Mitigation under Climate Change Aspects) aims to design approaches to meet the challenge of the future. The project is funded by the German Federal Ministry of Education and Research (BMBF) and was launched in October 2008. Within this project, a methodical concept to calculate extreme storm surges on the North Sea Coast is being developed in the subproject part of the Agency of Roads, Bridges and Waters. This method comprehends the different components of a storm surge and analyses their interactions to calculate an extreme storm surge event.

Storm surges in the North Sea are composed of wind surge, tide and sometimes an external surge. In order to calculate an extreme storm surge event, it is necessary to analyze these components and their interactions because investigation into the hydrodynamics and physics of storm surges have shown that the components have to be added non-linearly (e.g. Tang et al. 1996; Horsburgh and Wilson 2007;

\footnotetext{
${ }^{1}$ Free and Hanseatic City of Hamburg, Agency of Roads, Bridges and Waters, Sachsenfeld 3-5, 20097 Hamburg, Germany
} 
Jones and Davies 2007). This fact leads to a lower water level than in the case of linear superposition. In order to estimate the non-linear effects to their full extent and calculate a physically feasible storm surge event, these non-linear interactions have to be analyzed in depth. These analyses are recent additions in terms of a methodical concept to calculate extreme storm surges.

Having regard to the potential consequences of climate change for future extreme scenarios, sea level rise will be allowed for future scenarios of extreme storm surges in the XtremRisK project. The future development of the mean sea level has been projected in many recent studies. Yet the intensity of sea level rise is not ascertained. A review of recent studies to ascertain global, regional and local sea level rises is provided by Katsman et al. (2011) and Gönnert et al. (2010). The extent of sea level rise that is used for determining future extreme events should emerge from an investigation with a local perspective and is presented in the last section of this paper in a short overview.

In the following sections, the 2-method concept that has been developed is described in theoretical terms. Background acceptance is therefore described as well as the general development of the approach. The different analytical and methodical steps are defined. In the section after that, the practical application at the Cuxhaven tidal gauge will be presented. This practical application was closely connected with the development of the methodical concept. It offers a detailed look at practical details of the methodical approach. In the last section, analyses devoted to sea level rise, as the major consequence of climate change affecting storm surges on the North Sea coast, are presented in order to include these results in future extreme storm surge scenarios.

\section{THE METHODICAL APPROACH}

Extreme storm surges are defined as events which have a higher water level peak than all the very high storm surges that occurred before. In terms of calculating extreme storm surge scenarios, it is necessary to bear in mind the main proposition, namely that these events are physically feasible in terms of their meteorological and hydrodynamic basis. In relation to the presented method, both parts are taken into account.

The concept is based on the definition of storm surges by their wind surge curve. Taking the wind surge curve into consideration, it is possible to include the entire process of a storm surge in research analyses. Wind surge is generally calculated by subtracting the astronomical tide (or the mean tide) from the observed water level and reflecting the effect of the wind during the entire storm surge event in water level variation. Consideration of all tidal phases to identify storm surges is the key aspect of this definition because the surge-inducing wind and the tide occur independently from each other. In addition, examining the whole storm surge curve, together with the curves of all components during the storm event, makes it possible to include the hydrodynamic processes in the investigation. These processes influence the non-linear interactions and could vary depending on, for example, the tidal phase.

To construct extreme storm surge events it is essential to consider the highest observed occurrence of each component. Due to these extreme values that occurred in different storm surge events, one has to combine them in a new storm surge event. This process is following this approach. With regard to this intention, the following essential methodical steps are implemented in the 2-method concept: (i) analyzing the highest observed occurrence of each component and its hydrodynamic characteristic, (ii) analyzing the non-linear interactions in terms of interaction between tide and wind surge and the interaction between storm surge and external surge, and (iii) bringing these results together to calculate an extreme storm surge event. With regard to these three major analytical steps, different analyses are implemented for all components. Here the analytical basis of the 2-method concept becomes effective: in order to achieve comprehensive analysis, empirical and numerical methods are utilized in different methodical steps to gain comprehensive results for analyzing the components and the non-linear interactions between them. The consistency of the different methods' results allows an optimal ascertainment of the physical context and a validation of the methods used. The result of this 2-method concept is a realistic extreme scenario under present climate conditions. Furthermore, these scenarios are the basis for future scenarios of storm surges. These scenarios should be elaborated based on the fact that sea level rise is the main climate change factor to be added to the present possible storm surge 
scenarios. The potential increase in height of storm surges due to an increase in wind speed caused by climate change cannot be taken into account. The inclusion of changes in wind climate requires meteorological research in terms of approaching climatic models. Scientists with appropriate expertise in relation to meteorological and climatic analyses due to climatic modeling are participating in the XtremRisK project to control meteorological aspects of the results, but not with regard to developing storm scenarios under future conditions. In connection with this, sea level rise, representing the main issue of climate change relating to future storm surges and which can be modeled in the hydrological numerical model included in the project, is used for calculating the future extreme event. The calculated extreme event can be used for risk analysis as it is in the XtremRisK project. As a proviso, one has to say that for a complete risk analysis, storm surge levels with lower heights are needed as well. At the moment, the method presented could be used only to calculate the non-linear effect for very high storm surges, not for storm surges and high storm surges. These enhancements will be developed in a further project.

\section{Characteristics of the methodical approach}

Diversity of methodical approaches to analyze the storm surge components and their interaction processes are the most important characteristics of the 2-method concept. Therefore basic empirical and numerical approaches are utilized. Findings from these approaches are integrated into other methodical steps as well, as they are brought together and compared with each other in order to achieve knowledge about the plausibility of these results. In terms of the empirical methods, empiric-deterministic and statistical methods are applied. In comparison, numerical analyses could be done rather by using the same numerical model for all analytical steps or by using different numerical models for different numerical steps. Using different numerical models for different analytical steps could provide the opportunity to include scientists with specific expertise. This line of action will increase the quality and specificity of results for different components or interaction processes in the 2-method concept.

In general, the successful application of the 2-method concept is closely connected to the availability of data. Data on water level, wind surge, astronomical tide, external surge, the local wind situation and information about the general weather situation (especially for external surge events) are needed for the different analytical steps. The amount and quality of data are important factors for the assessment of the result and for the range of uncertainties.

Generally, as in most cases of scientific research, the qualities of results produced by the method presented are dependent on the amount of available data. Essential for the application of the method presented is the availability of water level data for a tidal gauge (as much as possible without influences from anthropogenic impacts), data based on astronomical tide forecasts, and wind data for the same period. Additionally, a collection of external surge data must be available. With regard to the marginal state of research due to the scientific background of external surges, the provision of data based on heights and serial data curves is rare at many tidal gauges. If there are data but not enough for a data base it must be developed using the methodical approach of residual surge. If there are no data about external surge at a tidal gauge, the data must be generated by, for example, calculating a residual surge. The information about the propagation of tides in terms of water level heights must be assigned to the propagation of external surges at the specific tidal gauge with regard to the propagation of external surges in the North Sea.

With regard to the available data, the following content is required in the different analytical steps for each component. At the beginning it is necessary to examine the physical possibility of the coincidence of the observed maximum values of the components. This result is essential before all components are combined in a new storm surge event. Therefore, in a first methodical step, the possibility of a simultaneous occurrence of a high spring high tide, external surges and high wind surge at tidal gauge Cuxhaven has to be inspected for all components. In a second step, methodical approaches are developed and applied to analyze each interaction between the storm surge components due to different genesis of single components and different hydrodynamic characteristics. On a theoretical basis, it is expected that in case of similar hydrodynamic genesis or basic/boundary conditions, such as the tide-surge interactions (wave/surge-movement from low to high tide) and surgespring tide interaction, the transfer of methods between these parts is allowed. 


\section{Analytical steps in the 2-method concept for analysing non-linear effects}

Based on this theoretical background, a huge number of methodical steps were developed to cope with the demands of the approach to analyzing the non-linear effects and to include them in a calculation of extreme storm surge scenarios. Table 1 gives an overview of the different methodical steps.

Table 1 Methodical steps of the 2-method concept to analyze the characteristic and non-linear interaction of the storm surge components

\begin{tabular}{|c|c|c|c|c|}
\hline $\begin{array}{c}\text { 1.Wind surge at tidal } \\
\text { phase }\end{array}$ & $\begin{array}{c}\text { 1.1 Wind surge } \\
\text { calculation: } \\
\text { Disjunction between } \\
\text { stochastical and } \\
\text { deterministic } \\
\text { processes }\end{array}$ & $\begin{array}{l}\text { 1.2 Wind surge-tidal } \\
\text { phase interaction: } \\
\text { empirical analysis } \\
\text { (observation data) by } \\
\text { using parameter } \\
\text { effective wind }\end{array}$ & $\begin{array}{l}1.3 \text { Numerical } \\
\text { modeling of wind } \\
\text { surge at different } \\
\text { tidal phases }\end{array}$ & \\
\hline 2.Spring tide & $\begin{array}{l}2.1 \text { Wind surge } \\
\text { calculation: } \\
\text { disjunction between } \\
\text { stochastical and } \\
\text { deterministic } \\
\text { processes }\end{array}$ & $\begin{array}{l}2.2 \text { Appliance of } \\
\text { results from } 1.2 \text { on } \\
\text { spring tide - wind } \\
\text { surge interaction using } \\
\text { a role of proportion } \\
\text { calculation }\end{array}$ & $\begin{array}{l}2.3 \text { Analyzing } \\
\text { spring tide-wind } \\
\text { surge interaction: } \\
\text { cross correlation } \\
\text { approach }\end{array}$ & $\begin{array}{l}\text { 2.4 Numerical } \\
\text { modeling } \\
\text { interaction } \\
\text { spring tide-wind } \\
\text { surge }\end{array}$ \\
\hline 3. External surge & $\begin{array}{c}\text { 3.1 Analyzing track } \\
\text { of cyclones which } \\
\text { produce external } \\
\text { surges }\end{array}$ & $\begin{array}{l}\text { 3.2 Developing level } \\
\text { of external surge in the } \\
\text { North Sea by } \\
\text { disjunction external } \\
\text { surge during storm } \\
\text { surge and without } \\
\text { storm surge. } \\
\text { Transformation on } \\
\text { non-linear effects }\end{array}$ & $\begin{array}{l}\text { 3.3 Numerical } \\
\text { modeling of } \\
\text { external surges }\end{array}$ & \\
\hline $\begin{array}{r}\text { 4. Extreme Storm } \\
\text { surge event }\end{array}$ & $\begin{array}{l}\text { 4.1 The empiric- } \\
\text { deterministic results } \\
\text { for non-linear } \\
\text { interactions will be } \\
\text { merged to achieve a } \\
\text { total height for a } \\
\text { storm surge }\end{array}$ & $\begin{array}{l}\text { 4.2 The developed } \\
\text { combination of } \\
\text { components is } \\
\text { modeled numerically }\end{array}$ & $\begin{array}{l}4.3 \text { Combination } \\
\text { of results from } 4.1 \\
\text { and } 4.2 \text { for a total } \\
\text { extreme storm } \\
\text { surge height }\end{array}$ & \\
\hline
\end{tabular}

With the results achieved using different approaches in the various steps described in table 1, the interaction between the components and the resultant reductions in a situation of an extreme storm surge event could be estimated.

The final step in this 2-method concept, the developed combination of components, is modeled numerically. Simultaneously, the empiric-deterministic results as well as the findings deduced from the numerical steps due to the combination of two components will be merged to achieve a total height for a storm surge including all three components.

\section{PRACTICAL APPLICATION OF THE 2-METHOD CONCEPT}

The development of the approach introduced here to calculate extreme storm surges was closely connected with practical analyses at tidal gauge Cuxhaven. The adjustment of results from different methodical steps in the practical example boosted the enhancement of the methodical steps. The final resultant methodical steps, which were described theoretically in the previous section, will be presented in the next section to give an impression about the applicability of the 2-method concept. 


\section{Numerical models}

The numerical models used for the methodical part of numerical simulations have to be suitable for the analyses. They have to be adequate both for the spatial application of the numerical model for the investigation area, and with regard to contents of the hydrodynamic basis for different components. In order to capture the large-scale processes which are responsible for significant water level changes in Cuxhaven, numerical model systems covering the North Sea and some parts of the Northeast Atlantic are used. The first modeling system, which is used for analyses at tidal gauge Cuxhaven by Bruss et al. (2010), is based on the Delft3D software based on Delft Hydraulics (Lesser et al. 2004) and consists of 3 sequentially nested models in two different resolutions. The two larger models of the North Sea and the Northeast Atlantic have the same resolution of around $10 \mathrm{~km}$ and are both based on an enhanced version of the Continental Shelf model, set up by Verboom et al (1992). The split-up of the Continental Shelf model is implemented in order to accomplish the isolated modeling of the two different surgegenerating processes and to enable a flexible overlay with the tide. Storm surges over the North Sea are modeled within the North Sea model whereas external surges are simulated in the NE Atlantic model. The German Bight model is nested in the North Sea model to increase the resolution along the German coastline to around $1 \mathrm{~km}$. The nesting sequence of Continental Shelf and German Bight model has been validated extensively elsewhere (Mayerle et al. 2005).

In order to obtain comprehensive results on the application of the 2-method concept at tidal gauge Cuxhaven, results from the German Federal Maritime and Hydrographic Agency are included to analyze the interaction between tide and wind surge. The basic numerical concept for this research is an operational model to analyze wind surge in the North Sea. This barotropic 2D Model, which is applied by the German Federal Maritime and Hydrographic Agency, covered the North Sea with a resolution of $10 \mathrm{~km}$. Tides, wind and atmospheric pressure forecasts (provided by the German Weather Service) and river run-off and external surges are used as boundary conditions for the simulation runs (Dick et al. 2001). In the course of integrating the operational model of the Federal Maritime and Hydrographic Agency into the approach, comprehensive expertise in terms of astronomical forecasting could be included in the project.

\section{Analyses of wind surge at tidal gauge Cuxhaven}

Wind surge is the proportionately biggest component of an extreme storm surge event. The wind surge is caused by wind-induced currents, basically resulting from the input of momentum at the boundary layer between atmosphere and hydrosphere. Investigations of wind surge characteristics identify the most effective wind direction that produces the highest surge. At tidal gauge Cuxhaven, Gönnert (2003) works out that westerly to north-westerly winds $\left(280-300^{\circ}\right)$ are the most effective winds for high wind surge at tidal gauge Cuxhaven. In terms of a workable wind parameter for the following methodical steps, the parameter "effective wind" should be used. It equates to a translation of the observed wind data from different wind direction and wind speed to the most effective wind direction. The resultant effective wind parameter is a measure for the relevance of the wind causing storm surges at the specific tidal gauge. For Cuxhaven, the effective wind direction is $295^{\circ}$ (Jensen et al. 2005). Investigation such as that by Dibbern \& Müller-Navarra (2009) gives information about methodical approaches to determine the most effective wind direction. At tidal gauge Cuxhaven, data of wind speed and wind direction (by courtesy of the German Weather Service) for periods of storm surge events were translated into the form of effective wind for further analyses.

A formula for calculating wind surge as a function of wind speed and wind direction exists only for a few tidal gauges on the German North Sea coast. Wind surge is therefore generally calculated by subtracting the astronomical tide (or the mean tide) from the observed tide. If the astronomical tide is being used for calculation, the wind surge also contains other factors that are not caused by the wind, such as the effect of local air pressure or the external surge.

At Cuxhaven, storm surges from 1843 onwards in terms of individual events and a continuous series of water level data from 1901 to 2008 (courtesy of the Cuxhaven Water and Shipping Authority and the German Federal Maritime and Hydrographic Agency), as well as the astronomical tide (see description in next section), are used for analyses. Based on these data, the resultant wind surge data were calculated and analyzed to establish the highest wind surge at tidal gauge Cuxhaven. The length of 
the time series which is considered here could minimize the uncertainties regarding the aim to identify the highest wind surge at a tidal gauge which is not influenced by external surges, etc. Generally, the level of uncertainties is decreasing as the length of time series that could be integrated into this approach increases. The uncertainties of the water level data depend on the uncertainties in the process of water level data collection (presently done mostly by automatic measuring stations). The analyses of the data showed that the maximum wind surge can occur in all tidal phases, but mostly occurs around tidal low water. The highest wind surge maxima also occurred around tidal low water. This confirms earlier studies which indicated that the maximum wind surge tends not to coincide with high tide (e.g. Keers 1968; Gönnert 2003; Horsburgh and Wilson 2007).

The highest wind surge event at tidal gauge Cuxhaven which is not influenced by an external surge consequently reached a height of $4.15 \mathrm{~m}$. This occurred in January 1976 around low tide. This wind surge curve is the basis for the following analyses and will be integrated into the approach as a fixed parameter in its amount.

Analyses of the development of wind surge at different tidal water levels and analyses of the expected effect of reduction of water level heights at the time of tidal high water are done in different empirical (Siefert 1998) and numerical (DHI cited by Siefert et al. 1989, Bruss et al. 2010) steps.

Additionally, the ratio between wind surge height around low water and around high water and the relations with regard to wind speed and tide are analyzed (Gönnert and Sossidi 2011). The effective wind is calculated on the basis of the wind directions that produce the highest wind surge at tidal gauge Cuxhaven. It describes the wind speed converted to the wind direction that produces the highest wind surge. The analysis of wind surge depending on effective wind in each tide phase showed the relationship between the height of wind surge around high tide and around low tide. At tidal gauge Cuxhaven, the wind surge at high tide amounts to 82 to $94 \%$ of the wind surge around low tide. The amount of the remaining wind surge rises with the effective wind speed.

\section{Analyses of spring tide at tidal gauge Cuxhaven}

The mean tidal curve is the arithmetical average tidal curve at a specific gauge over a certain time period. In this process, tidal curves of different moon phases are averaged so that the differences of spring and neap tide are indeterminable. Past analyses of storm surges were mostly based on the mean tide because it is a statistical term which requires only a relatively short calculation period. In the past it was mathematically difficult and time-consuming to calculate the astronomical tide for any one day. Nowadays most computers have the required processing power. The Agency of Roads, Bridges and Waters extended two existing programs for calculating the astronomical tide with the help of the Federal Maritime and Hydrographic Agency. It results from the combination of harmonically calculated tidal curves (using the commercially obtainable program Tidal Analysis Software Kit 2000 [TASK 2000] from the Proudman Oceanographic Laboratory) and the non-harmonically calculated astronomical tide with the program of the Federal Maritime and Hydrographic Agency. Using this combination, tidal-inducing force at each single point in time could be considered as well as the local share in friction and reflection processes. Based on this calculation method, in which, among other things, astronomical forecasts for tidal high and tidal low water from 1918 to 2008 were used (courtesy of the German Federal Maritime and Hydrographic Agency), astronomical tides for all storm surge events since 1901 at tidal gauge Cuxhaven were generated and analyzed. In addition, for the last decade the astronomical tides could be generated for all seasons and integrated into the analysis. The highest values of spring high tide at the tidal gauges were detected by subtracting the mean high tide from astronomical high tide. Thus it is possible to divide the stochastic process from astronomical effects and to analyse the tide-surge interaction. In Cuxhaven the highest level is $60 \mathrm{~cm}$ above the mean high tide.

\section{Analyses of external surge at tidal gauge Cuxhaven}

External surges are generated in the North-eastern Atlantic because of air pressure variations that are generated by fast passing cyclones. They produce observable waves on the water surface as well as internal waves in the water body. The propagation of an external surge into the North Sea takes place primarily when the track of the causative cyclone leads from the sea areas between Ireland and Iceland to mid-Norway (Schmitz et al. 1988). These waves propagate to the North Sea similar to a tidal wave, but independently of the tidal phase and any periodic regularity. They travel through the North Sea in 
an anti-clockwise direction. External surges are calculated from observed tide data at tidal gauge Cuxhaven that were recorded by the German Federal Maritime and Hydrographic Agency. Based on Gönnert (2003), a collection of data for analyzing external surges is available for the time series between 1971-1995 (with a lack of data between 1974 and 1978). The outcome is a collection of 73 external surge events.

The maximum height of an external surge recognized at Cuxhaven was $109 \mathrm{~cm}$. This external surge reached $108 \mathrm{~cm}$ in Aberdeen. It did not coincide with a storm surge. The highest external surge that coincided with a storm surge reached a peak level of $1 \mathrm{~m}$ at Cuxhaven.

In addition to the empiric analysis, a numerical approach to analyzing the external surge in the North Sea was used by Bruss et al. (2010). The aim of this analysis was to determine its propagation in the North Sea. This analysis generates important information about the development and propagation of external surges in the North Sea region and their heights. In addition, empirical research about the characteristic of external surges with regard to the meteorological situation was conducted in order to increase the knowledge about the hydrodynamic characteristics of this component. This analysis emphasizes the following correlation between the development in height and the meteorological situation: external surges will increase if the cyclone tracks southwards and influences the water body of the North Sea (and sometimes produces a storm surge). In contrast, external surges decrease (or stay more or less at the same level) if the cyclone tracks northwards and has no relevant influence on the water body of the North Sea (Gönnert and Sossidi 2011).

\section{Analyzing the non-linear interactions at tidal gauge Cuxhaven}

According to the analyses presented with regard to the hydrodynamic characteristics of each component, as well as the determination of their highest observed occurrence at tidal gauge Cuxhaven, the non-linear interactions between surge and spring tide and the interaction between wind surge and external surge should be analyzed. In order to analyze the interaction between tide and wind surge, a cross-correlation is applied. Consideration of the correlations indicates a higher correlation between wind surge and astronomical tide in cases of high and very high storm surges than between mean tide and high storm surge events. The observed effect of the astronomically induced deflection of water level on the wind surge curve and peak in this methodical step could be evaluated as rather small.

The analysis of the relation between the height of wind surge around high tide and around low tide clarified the increasing relevance of the wind as wind speeds increase. The results of this analysis can be transferred to the astronomical dissimilarity. Hence the empirical analyses of the development of wind surge at different tidal water level, the expected effect of a reduction in water level heights at the time of tidal high water (Siefert 1998, DHI cited by Siefert et al. 1989, Bruss et al. 2010), and the extent of the reduction in wind surge caused by shifting from low water to high water can be adapted to make out the reduction in the effects of spring tide on storm surge water levels. With regard to the connection between the overall water level and the reduction resulting from non-linear processes, the calculation of the spring tide decrease must include wind surge. Based on this information, this result is applied in terms of a statistical approach by using a rule of proportion. If there is a wind surge of 3.70 $\mathrm{m}$ and spring tide of $60 \mathrm{~cm}$, the non-linear effects will reduce the spring tide to $13 \mathrm{~cm}$.

As regards a numerical approach, the analysis of Dick (2000) is brought into the application at tidal gauge Cuxhaven. In his analysis, Dick coupled a high wind surge with a spring tide to analyse the reduction in spring tide resulting from the interaction. The results of this analysis confirm the hypothesis of a decreasing influence of spring tide in combination with an increasing wind speed and wind surge height. Taking the water level height and wind surge of specific storm surge events into consideration, Dick ascertained a spring tide reduction in the magnitude of $16 \%$ to $31 \%$ based on its initial height subjected to the specific wind surge. In order to establish a detailed comparison and transfer of results to the analyses being presented, it is necessary to start a comparison based on the same level of wind surge height. In the case of a wind surge height of $375 \mathrm{~cm}$ (which conforms to the highest wind surge at tidal high water that is analyzed in the aforementioned steps), spring tide is reduced to a height of $27 \%$. In terms of a further increase in height of wind surge/water level, which corresponds to the component of an external surge in the study presented here, the analysis of Dick (2000) postulates a reduction in spring tide of up to $16 \%$ of its initial height. Translating this result to the maximum spring tide ascertained at tidal gauge Cuxhaven, this will be reduced to a height of 9.5 
$\mathrm{cm}$. In conclusion, the astronomical dissimilarity in combination with the wind surge of $3.70 \mathrm{~m}$ is reduced to a height of $10 \mathrm{~cm}$ with regard to the non-linear interaction of the components.

Basic analyses with regard to the hydrodynamic characteristics of external surges presented above emphasize the important influence of the meteorological conditions for the generation and propagation of external surges. This finding must be transferred to the analyses of non-linear interactions between external surges and other components. With regard to these findings, an empirical step is established to analyze the interaction between external surge and storm surge in relation to the meteorological conditions. As a result, two different situations could be classified: the combination of external surge and storm surge could be initiated by two different extra tropical cyclones as well as by the same extra tropical cyclone. The first situation, with two different cyclones which generate the storm surge and external surge independently from each other, could be observed in Cuxhaven, e.g. on 4 January 1983. The second situation could be observed e.g. on 22.01.1993 and 16/17 February 1962.

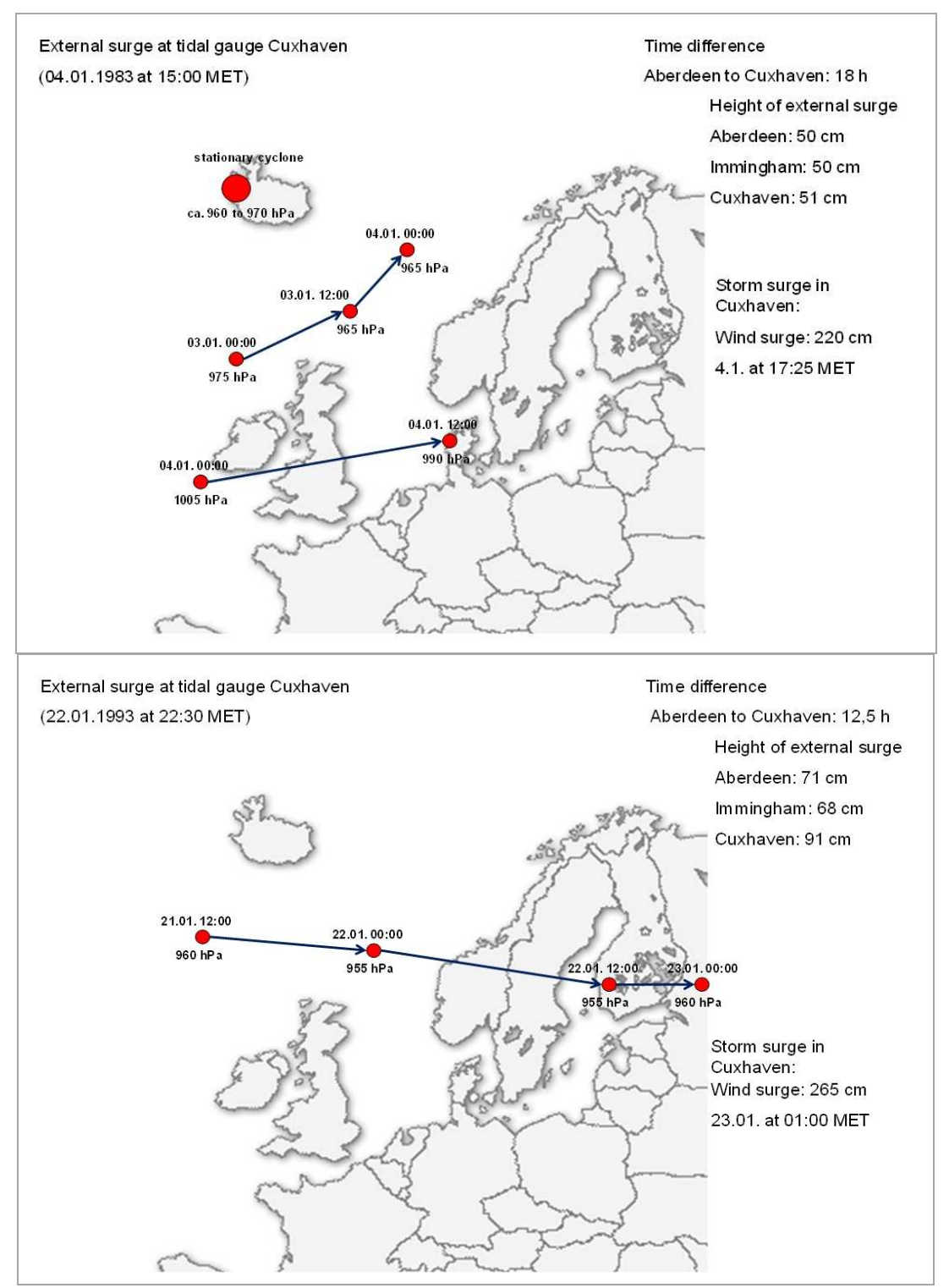

Fig.1: Track of cyclones in terms of a combined occurrence of storm surge and external surge. Upper figure: event of 04.01.1981, two different cyclones generate storm surge and external surge independently from each other; lower figure: event of 22.01.1993, one cyclone generates storm surge and external surge 
In order to analyze the interactions between external and wind surge, cyclones which feature the southern track and potentially have an effect on the water body of the North Sea should be obviated due to undefined influences. These effects could include effects of air pressure and air pressure variations over the sea as well as additional wind. To prevent the peak of the external surge combined with the extreme storm surge from containing alterations in the water level caused by these influences, only external surges that occurred without a simultaneous storm are taken into account. The average decrease in these external surges is $30 \%$.

The highest observed external surge reached $1.08 \mathrm{~m}$ at tidal gauge Aberdeen. If it is reduced by $30 \%$ on its way to Cuxhaven, it arrives in Cuxhaven with a peak of about $80 \mathrm{~cm}(77 \mathrm{~cm})$. This equates to the peak of the external surge that was observed during the storm surge of 1962 (Laucht 1968).

Compared to the numerical simulation of Bruss et al. (2010), the reduction in external surge is almost similar in combination with wind surge and spring tide in comparison to the reduction in the external surge, as per the empirical results, from $109 \mathrm{~cm}$ to $80 \mathrm{~cm}$. Taking the range of variation in the data $(8 \%-43 \%$ decrease) into account, the potential height of an external surge would be $60 \mathrm{~cm}$ to 100 $\mathrm{cm}$. The external surge at tidal gauge Cuxhaven is estimated to have a height of $77 \mathrm{~cm}$.

\section{The extreme storm surge event}

In the last steps of the 2-method concept, the results from all different methodical steps described before must be brought together in order to calculate the total height of the extreme storm surge event. In line with the methodical basis, both empirical and numerical steps are included with the objective of bringing together all components in consideration of the non-linear interactions.

The empirical step includes all findings and intermediate results so that the extreme storm surge event can be generated. The result is a storm surge curve for the whole period of the extreme storm surge event. The storm surge curve comprises the wind surge curve, the external surge curve and an astronomical tide curve that reflects the mean tide condition plus the detected effect of the astronomical dissimilarity.

Parallel to this empiric-deterministic procedure, the total water level will be simulated numerically by including all components in the model run (Bruss et al. 2010). The difference between the results of the numerical and deterministic-empirical approaches (about $\pm 10 \mathrm{~cm}$ ) is insignificant. Related to these insignificant differences, the total height of the extreme event is calculated to be $620 \mathrm{~cm}+\mathrm{NN}$ at tidal gauge Cuxhaven by applying the 2-method concept presented here.

\section{UNCERTAINTIES}

With regard to comprehensive analyses and a comprehensive evaluation of the storm surge scenarios developed here, it is necessary to examine the uncertainties resulting from the different methodical approaches. In table 2, the set of uncertainties in this approach is shown in relation to the single methodical steps. In addition to a general description of the source of uncertainties, a quantification for practical application at tidal gauge Cuxhaven is added wherever possible. 
Table 2: Uncertainties for each methodical steps of the 2-method-concept

\begin{tabular}{|c|c|c|c|c|}
\hline $\begin{array}{l}\text { 1.wind surge } \\
\text { at tidal } \\
\text { phase }\end{array}$ & $\begin{array}{l}\text { 1.1. Wind surge } \\
\text { calculation: } \\
\text { - uncertainties due to } \\
\text { water level capture } \\
\text { - uncertainties due to } \\
\text { smoothing of water } \\
\text { level curve } \\
\text { Uncertainties due to } \\
\text { astronomical data from } \\
\text { tidal table }(+/-5 \mathrm{~cm}) \\
\text { - uncertainties due to } \\
\text { calculation of } \\
\text { astronomical tide }(+/- \\
1 \mathrm{~cm})\end{array}$ & $\begin{array}{l}\text { 1.2 Wind surge - tidal } \\
\text { phase interaction: } \\
\text { Uncertainties due to: } \\
\text { - collection of water } \\
\text { level and wind data } \\
\text { - extent of analyzed } \\
\text { data } \\
\text { - "clarity" of wind } \\
\text { surge from other } \\
\text { components } \\
\text { In comparison to other } \\
\text { analyses }(\text { Cux }) \text { : } \\
(-) 2 \%-(+) 1 \%\end{array}$ & $\begin{array}{l}\text { 1.3. Numerical modeling } \\
\text { wind surge at different } \\
\text { tidal phase: } \\
\text { - uncertainties of the model } \\
\text { Uncertainties of numerical } \\
\text { model (Bruss et al. } 2010) \text { : } \\
\text { verification of modeled } \\
\text { water level at } 3 \text { storm } \\
\text { surges: }+0.22-(-) 17 \mathrm{~cm}\end{array}$ & \\
\hline 2. Spring tide & $\begin{array}{l}2.1 \text { Disjunction } \\
\text { between stochastical } \\
\text { and deterministic } \\
\text { processes: } \\
\text { - see } 1.1\end{array}$ & $\begin{array}{l}2.2 \text { Application of } \\
\text { results from } 1.2 \text { to } \\
\text { spring tide - wind } \\
\text { surge interaction using } \\
\text { a role of proportion } \\
\text { calculation: } \\
\text { - see } 1.2\end{array}$ & $\begin{array}{l}2.3 \text { Analyzing spring tide- } \\
\text { wind surge interaction: } \\
\text { Cross correlation } \\
\text { approach: } \\
\text { - accuracy of cross- } \\
\text { correlation analysis: } \\
\text { accuracy of the } \\
\text { hydrological data and its } \\
\text { temporal resolution }\end{array}$ & $\begin{array}{l}\text { 2.4. Numerical modeling } \\
\text { interaction spring tide-wind } \\
\text { surge: } \\
\text { - uncertainties of the model: } \\
\text { - different drag coefficients } \\
\text { have influence on wind } \\
\text { surge calculation } \\
\text { - model is sensitive to } \\
\text { different types of wind field } \\
\text { data } \\
\text { Uncertainties of numerical } \\
\text { model at tidal gauge } \\
\text { Cuxhaven (Dick et al., } \\
\text { 2001): } \\
\text { Bias: } 6.6 \text { cm; standard } \\
\text { deviation at HW: } 18 \mathrm{~cm} \\
\text { - uncertainties due to } \\
\text { transfer of results to } \\
\text { different storm surge event }\end{array}$ \\
\hline $\begin{array}{l}\text { 3. External } \\
\text { Surge }\end{array}$ & $\begin{array}{l}\text { 3.1 Analyzing track of } \\
\text { cyclones which } \\
\text { produce external } \\
\text { surges: } \\
\text { - uncertainties due to } \\
\text { data collection } \\
\text { Uncertainties due to } \\
\text { calculation of residual } \\
\text { surge: approx. + / - } \\
0.10 \mathrm{~m} \\
\text { - first analyses of this } \\
\text { topic, no comparative } \\
\text { analyses available }\end{array}$ & $\begin{array}{l}3.2 \text { Analyzing external } \\
\text { surge during storm } \\
\text { surge and without. } \\
\text { Transformation on } \\
\text { non-linear effects: } \\
\text { - see } 3.1 \\
\text { - uncertainty of } 8 \% \text { - } \\
43 \% \text { due to reduction } \\
\text { caused by non-linear } \\
\text { effects (= } 60-100 \mathrm{~cm} \\
\text { at tidal gauge } \\
\text { Cuxhaven) }\end{array}$ & $\begin{array}{l}\text { 3.3 Numerical modeling of } \\
\text { external surges } \\
\text { - uncertainties in the } \\
\text { empirical determination of } \\
\text { external surges } \\
\text { - uncertainties in the } \\
\text { accuracy of the } \\
\text { meteorological hind casts } \\
\text { - uncertainties about the } \\
\text { influence of the model } \\
\text { extending into the North } \\
\text { Atlantic } \\
\text { Uncertainties of numerical } \\
\text { model (Bruss et al. } 2010) \\
\text { in terms of differences in } \\
\text { modeled and empirically } \\
\text { calculated external surges: } \\
\text { Cuxhaven: (-)0,20m- } 0,20 \\
\text { m } \\
\text { Aberdeen: (-)0,11m- } 0,29 \\
\text { m }\end{array}$ & \\
\hline \multicolumn{4}{|c|}{$\begin{array}{l}\text { Range of quantitative results for interaction wind surge - spring tide at Cuxhaven results from all } \\
\text { methodical steps }\end{array}$} & $+3 \mathrm{~cm}$ \\
\hline \multicolumn{4}{|c|}{$\begin{array}{l}\text { Range of quantitative results for interaction wind surge - external surge at Cuxhaven results from } \\
\text { all methodical steps }\end{array}$} & $(-) 13 \mathrm{~cm}-(+) 23 \mathrm{~cm}$ \\
\hline
\end{tabular}




\section{SCENARIOS FOR FUTURE EXTREME STORM SURGES}

The extreme storm surge event described in the previous chapters can be used as a basis for evaluating future extreme storm surge scenarios. With regard to future climatic changes, which could affect storm surges in both their intensity and probability of occurrence, changes in wind climate as well as sea level rises generally have to be taken into account. In general, the effect of rising sea level is the most important impacting factor for future storm surge characteristics. To project estimations of impacts of future sea level rise on very high storm surge events, the anticipated potential sea level rise has to be identified. Furthermore, the combination of rising sea level and high storm surges and their non-linear effects (and/or the determined extreme storm surge event) must be analyzed.

The development of the rising sea level is projected in a large number of research studies which differ in their spatial resolution as well as in their methodical approaches and the future climate emissions scenarios which are included. It is therefore important to differentiate between global, regional and local projections of sea level rise. The effect and extent of different components of the rising sea level (thermal expansion, contribution of glaciers, contribution of Arctic and Antarctic ice sheets, etc.) could differ in their spatial resolution of research areas.

The International Panel on Climate Change (IPCC) binds a huge quantity of research results in terms of climate change issues. Investigations and results due to past and future sea level variations are in included as well. Based on this scientific background, the 2007 IPCC report projects an increase of $18-59 \mathrm{~cm}$ in global sea level up to 2100 (in consideration of recent studies in relation to potential scaled-up ice sheet balance, the projection will be increased by 10-20 cm) (IPCC 2007). With regard to the rapidly increasing quantity and quality of analyses of future sea level rise, Gönnert et al. 2010 work out a comparison of the current sea level analysis. The analysis provides a very high range between different investigations and methodical approaches. On a global level, a range of values between $(-5)$ and $+140 \mathrm{~cm}$ is worked out (Gönnert et al. 2010). It is important to point out that the projection by the IPCC (2007) reflects only the lower third of the detected range of values by Gönnert et al. (2010). Examination of research results at regional level on the North Sea coast in the same analysis by Gönnert et al (2010) emphasizes a range of projects from (-5) up to $+115 \mathrm{~cm}$ for the North Sea region up until 2100. These results are comparable to the results of Katsman et al. (2011) in their dimensions. These authors develop a plausible high-end scenario for a global mean sea level rise of $0.55-1.15 \mathrm{~m}$. On a local scale, Katsman et al. (2011) project a mean sea level rise of between 0.40 and $1.05 \mathrm{~m}$ on the Dutch North Sea coast under high-end conditions up until 2100.

Based on these results, a mean regional sea level rise for 2100 must be estimated in order to construct one possible future extreme storm surge events. Within the XtremRisK project two different scenarios have been calculated in consideration of the impact of future sea level rise. Up to 2100 $+40 \mathrm{~cm}$ and $+80 \mathrm{~cm}$ increase in water level with regard by rising sea level is assumed in the project.

\section{SUMMARY}

The XtremSturmflut method, presented here, is a new way of calculating extreme storm surges and can be used within new design concepts. This method, using a 2-method-concept, meets the purpose of the XtremRisK project to calculate physically feasible storm surge events. This purpose is done here on the basis of observed storm surge events at the specific research gauge. The new method implies detailed analyses of the single storm-surge components tide, external surge from the Atlantic and wind surge. Separation of the water level in its different wind surge components is a new development in storm surge research to analyze extreme storm surge events. Taking into account the progress of the components during the storm surge event, which are combined stochastically in storm surge events, consideration of the meteorologically and physically feasibility of this combination could take place. Following, all components could be brought together to the same event where their non-linear interactions could be considered by combining deterministic-empirical, statistical and numerical methods. Resultant from these analyzes reduction actors for the non-linear effects could be developed in terms of very high storm surge events.

This method combination provides the best way of analyzing the physical relations. The time lapse and characteristics of extreme storm surges can be calculated by combining these results using the 
empirical method. Comparing results of numerical and empirical interactions verifies the reliability of the methodological appendages. Only when two different methods produce comparable results can basic assumptions be verified and results are identified as correct. The application of this two-method concept to the Hamburg gauge Cuxhaven produces reliable results. Related to the total height of $600 \mathrm{~cm}$ for the extreme event, wind surge, the difference between the results of the numerical and deterministicempirical models is insignificant at approximately $20 \mathrm{~cm}$. The amount of available data and its length with regard to time series is path breaking for the feasibility of the approach. In terms of analyzing lower storm surges it would definitely be necessary to apply a 2-method concept to comprise the different physical interactions in these situations. Application at different tidal gauge Cuxhaven and Hörnum in the XtremRisK project illustrated the potential for transfer of methodology.

\section{ACKNOWLEDGMENT}

We would like to thank our partners from the XtremRisk project from the Universities of Braunschweig, Hamburg-Harburg and Siegen for a pleas-ant and effective cooperation. Additionally we would like to thank the cooperative and consultative partners. For the provided data we thank the Federal Maritime and Hydrographic Agency, the Shipping Administration of the Federal Government, the German Weather Service and the LKN-SH (Schleswig-Holstein Agency for Coastal Defence, National Park und Marine Conservation).

The project is funded by the German Federal Ministry of Education and Research (BMBF) through the project management of Projektträger Jülich under the grant number 03F043B.

\section{REFERENCES}

Bruss, G., G. Gönnert and R. Mayerle. 2010. Extreme scenarios for flood protection at the North Sea, A numerical study, Proceedings of the 32nd International Conference on Coastal Engineering (ICCE) Shanghai.

Dibbern, S. and S. Müller-Navarra. 2009. Wasserstände bei Sturmfluten entlang der nordfriesischen Küste mit den Inseln und Halligen, Die Küste, 76, 205-224.

Dick, S. 2000. Die Sturmflut am 3. Dezember 1999 - Fallstudien mit dem Windstaumodell des BSH, Presentation at the workshop on storm surges organized by the Federal Waterways Engineering and Research Institute, Hamburg, Germany, 16.11.2000, Head of the Directorate Forecasting, Federal Maritime and Hydrographic Agency, 2000. Contact for questions: stephan.dick@bsh.de.

Dick, S., E. Kleine, S. Müller-Navarra, H. Klein and H. Komo. 2001. The Operational Model of BSH (BSHcmod) - Model description and validation, Berichte des Bundesamtes für Seeschiffahrt und Hydrographie, 29.

Gönnert G. 2003. Sturmfluten und Windstau in der Deutschen Bucht. Charakter, Veränderungen und Maximalwerte im 20. Jahrhundert, Die Küste 67, 185-365.

Gönnert G., S.K. Dube, T. Murty T. and W. Siefert. 2001. Global Storm Surges, Die Küste 63, Hamburg.

Gönnert G., J. Jensen, H. von Storch, S. Thumm, Th. Wahl and R. Weisse. 2010. Der Meeresspiegelanstieg - Ursachen, Tendenzen und Risikobewertung, Die Küste 76, 225-256.

Horsburgh, K.J. and C. Wilson. 2007. Tide-surge interaction and its role in the distribution of surge residuals in the North Sea, Journal of Geophysical Research 112 (C8), Art. No. C08003. 10.1029/2006JC004033.

IPCC: Climate Change 2007: The Physical Science Basis. Contribution of Working Group I to the Fourth Assessment Report of the Intergovernmental Panel on Climate Change, Solomon, S.; Qin, D.; Manning, M.; Chen, Z.; Marquis, M.; Averyt, K.B.; Tignor M.; Miller, H.L. (eds.), Cambridge University Press, Cambridge, United Kingdom and New York, NY, USA, 2007.

Jensen, J., C. Mudersbach, I. Bork, S. Müller-Navarra, C. Koziar and V. Renner. 2005. Modellgestützte Untersuchungen zu Sturmfluten mit sehr geringen Eintrittswahrscheinlichkeiten (MUSE) - Abschlussbericht zum BMBF Forschungsvorhaben 03KISO039 (KFKI Fördernummer 78), Universität Siegen, Siegen.

Jones, J.E. and A.M. Davies. 2007. Influence of non-linear effects upon surge elevations along the west coast of Britain, Ocean Dynamics, 57, 401-416. 
Katsman C.A., A. Sterl, J.J. Beersma, H.W. van den Brink, J.A. Church, W. Hazeleger, R.E. Kopp, D. Kroon, J. Kwadijk, R. Lammersen, J. Lowe, M. Oppenheimer, H.P Plag, J. Ridley, H. von Storch, D.G Vaughan, P. Vellinga, L.L.A. Vermerrsen, R.S.W. van de Wal and R. Weisse. 2011. Exploring high end scenarios for local sea level rise to develop flood protection strategies for a low lying delta - the Netherlands as an example, Climatic Change (published online).

Keers, J.F. 1968. An empirical investigation of interaction between storm surge and astronomical tide on the east coast of Great Britain, Ocean Dynamics, 21(3), 118-125.

Laucht, H. 1968. Über hohe Sturmfluten und ihre Häufigkeit in Hamburg, Schriftenreihe der Behörde für Wirtschaft und Verkehr der Freien und Hansestadt Hamburg, 4.

Lesser, G., J. Roelvink, J. van Kester and G. Stelling. 2004. Development and validation of a threedimensional morphological model, Coastal Engineering, 51(8-9), 883-915.

Mayerle, R., J. Wilkens, C. Escobar and W. Windupranata. 2005. Hydrodynamic Forcing Along the Open Sea Boundaries of Small-Scale Coastal Models, Die Küste, 69, 203-228.

Schmitz, H.P. and D. Habicht. 1988. Barotropic numerical experiments on external surge generation at the edge of the north-western European shelf, Gerlands Beiträge zur Geophysik, 97/5, 422-437.

Siefert, W.: Bemessungswasserstände 2085 A entlang der Elbe. Ergebnisse einer Überprüfung durch die Länderarbeitsgruppe nach 10 Jahren (1995/96), Die Küste, 60, 227-255, 1998.

Siefert, W. and K. Havnø. 1989. Sturmflutuntersuchungen für die Elbe mit den mathematischhydraulischen Modellen des Dänischen Hydraulischen Institutes, Hamburger Küstenforschung, 46.

Small, C. and R.J. Nicholls. 2003. A global analysis of human settlement in coastal zones, Journal of Coastal Research, 19, 584-599.

Tang Y.M., R. Grimshaw, B. Sanderson and G. Holland. 1996. A Numerical Study of Storm Surges and Tides, with Application to the North Queensland Coast, Journal of Physical Oceanography, 26, 2700-2711.

Verboom, G., J. Ronde and R. Dijk. 1992. A fine grid tidal flow and storm surge model of the North Sea, Continental Shelf Research, 12 (2/3), 213-233. 